ANUARIO DE Estudios MEDIEVALES

48/1, enero-junio de 2018, pp. 49-80

ISSN 0066-5061

https://doi.org/10.3989/aem.2018.48.1.02

\title{
LA CIUDAD Y EL REY: RENOVACIÓN DE LA RED URBANA DE NAVARRA AL FINAL DE LA EDAD MEDIA
}

\author{
THE CITY AND THE KING: THE RENOVATION OF THE URBAN NETWORK \\ OF NAVARRE AT THE END OF THE MIDDLE AGES
}

\author{
ELOÍSA RAMÍREZ VAQUERO \\ Universidad Pública de Navarra \\ http://orcid.org/ 0000-0003-4852-6303
}

\begin{abstract}
Resumen: Tras el análisis del desarrollo de la red urbana de Navarra hasta los inicios del siglo XIII, realizado en trabajos anteriores, se observaba una trama densa. Ésta se había formado al hilo de diversos condicionantes: el interés regio, el control del espacio y la consolidación de rutas preferentes de comunicación. Se intuía además que, a partir de ese momento y hasta el final de la Edad media, los elementos decisivos para la articulación de un sistema urbano jerarquizado serían otros. Analizar este proceso, entre 1219 y el inicio del siglo XVI, es el objetivo de este trabajo. Destaca ahora la consolidación de cuatro -máximo cinco- focos urbanos esenciales, con particular relevancia de tres -Pamplona, Tudela, Estella- definidos sobre todo por el peso político, administrativo, económico y eclesiástico de uno de ellos, y el administrativo y económico -sobre todo- de los otros dos. La trama urbana del final de la Edad Media se sostiene sobre estos puntos esenciales; la jerarquía urbana del reino y su sistema de articulación adquiere una forma más simple y acorde con los rasgos esenciales de las realidades urbanas y con las dimensiones del propio reino. Palabras clave: Navarra; historia urbana; Baja Edad Media.
\end{abstract}

Abstract: Research conducted in earlier works studied the development of Navarre's urban network until the beginning of the $13^{\text {th }}$ century and revealed it to be both dense and complex. Royal interests, land control, and the consolidation of preferred communication routes were the underlying causes for this complexity. However, the elements that contributed to this complexity differ from those that led to the development of the hierarchical urban system from the $13^{\text {th }}$ century until the end of the Middle Ages. The objective of this paper is to analyse the transformation that occurred from 1219 to the beginning of the $16^{\text {th }}$ century. The paper highlights the consolidation of four, at most five, focal urban sites, with a particular emphasis on three -Pamplona, Tudela, and Estella- of which one is defined by its political, administrative, economic and ecclesiastical importance and the other two by their administrative and economic importance. Ultimately, the development of the urban network towards the end of the Middle Ages was propelled by the following essential points: the urban hierarchy of the kingdom and its system of operation acquired a simpler form that was in accordance with the essential traits of the urban realities and dimensions of the kingdom itself.

Keywords: Navarre; urban history; Late Middle Ages.

\section{SUMARIO}

1. Introducción.- 2. El punto de partida: la red construida entre 1076 y 1219.3. La trama urbana bajomedieval: ss. XIII-XVI.- 3.1. Los nuevos estatutos urbanos: ss. XIII-XVI.- 3.2. Nuevos rangos: otro sistema urbano que nos dirige hacia los ss. XVI y XVII.- 4. El sistema urbano navarro a finales de la edad media. Conclusiones.- 5. Bibliografía citada.

Cómo citar este artículo: Ramírez Vaquero, Eloísa (2018), La ciudad y el rey: renovación de la red urbana de Navarra al final de la Edad Media, "Anuario de Estudios Medievales" 48/1, pp. 49-80. https://doi.org/10.3989/aem.2018.48.1.02

Copyright: (C) 2018 CSIC. Este es un artículo de acceso abierto distribuido bajo los términos de la licencia de uso y distribución Creative Commons Reconocimiento 4.0 Internacional (CC BY 4.0). 


\section{INTRODUCCIÓN ${ }^{1}$}

Como ya se ha señalado en otras ocasiones, Navarra es un espacio relativamente pequeño, dotado de algunos elementos singulares; cabría definirlo como un reino con escala de condado o ducado francés o germánico. Junto a la ventaja de presentar un marco de análisis dotado de interesantes aspectos ideológicos, políticos y de gestión, que al mismo tiempo resulta razonablemente abarcable, esta circunstancia también implica algunos contratiempos para el estudio del desarrollo urbano. Destacan quizá, entre ellos, la intensa proximidad del poder regio que las reducidas dimensiones favorece -con sus ventajas e inconvenientes-; la falta en este caso de un desarrollo equilibrado y constante de la capitalidad efectiva del reino -a pesar del peso ideológico que siempre tiene Pamplona, pocas veces es residencia regia y tarda en consolidarse como verdadero centro administrativo de la monarquía-; la configuración de aglomeraciones de población de tamaño medio, cuando no pequeño; o el desarrollo de mercados igualmente reducidos, vinculados a las redes de comunicación y la esfera de interés de esos pequeños núcleos urbanos. Con todo, el reino puede ser un laboratorio interesante para el punto de vista de este dossier, que invita a analizar, y en este caso replantear, cuestiones de jerarquía y organización del territorio.

La historiografía navarra ha solido considerar el análisis urbano desde la perspectiva de las ciudades individualizadas, cada una analizada a lo largo de todo su recorrido formativo, aunque también se cuenta con algunas visiones de conjunto, como la que inauguró hace años $\mathrm{J} \mathrm{M}^{\mathrm{a}}$. Lacarra ${ }^{2}$. El hilo conductor de ésta, y de las subsiguientes visiones globales, ha tenido siempre mucho que ver con la secuencia de concesiones de estatutos urbanos -fueros- y con los indudables vínculos de ese proceso fundacional con la ruta jacobea, desde el siglo XI al XV ${ }^{3}$. Conocemos bastante bien, por tanto, la sucesión de fundaciones, los contenidos de cada estatuto y la estructura urbana de cada caso; no se trata, por tanto, de volver sobre ello o de realizar aquí un balance historiográfico completo. Cabe destacar, sin embargo, que el desarrollo urbano se contempla, en su conjunto, como respuesta a las necesidades de articulación de una red viaria fuertemente ligada a las peregrinaciones, en

\footnotetext{
${ }^{1}$ Abreviaturas utilizadas: AGN = Archivo Real y General de Navarra; CO_DOCUMENTOS = Cámara de Comptos, Documentos. GEN = Gran Enciclopedia de Navarra (vid. Bibliografía)

${ }^{2}$ Lacarra 1950. En todo caso, un somero balance historiográfico de la producción hasta 2002 aparece en Martín Duque 2002, desde p. 47. El cuestionario de partida en el volumen que recoge el trabajo de éste último respondía a una visión algo distinta del proceso urbanizador, ligada a aspectos jurídicos, demográficos y espaciales.

${ }^{3}$ Aparte de lo indicado en la nota precedente, cabe mencionar diversos trabajos de J. Carrasco en esta línea, por ejemplo Carrasco 1999, 2003.
} 
alguna medida a la conquista del valle del Ebro - por la conquista de Tudelay, sobre todo, relacionada con la necesidad de ofrecer un adecuado marco jurídico a las nuevas realidades sociales. Al mismo tiempo, cabe considerar que el proceso va desarrollándose paulatinamente, con una evidente etapa de más intensificación fundacional entre el final del siglo XI y el final del XII, generando un denso tejido donde destacan, sobre todo, los principales hitos del "Camino" y el centro urbano por excelencia del valle del Ebro navarro, Tudela.

Sin dejar de lado una parte de estos puntos de vista, se propuso no hace mucho un análisis un poco diferente ${ }^{4}$, proponiendo una trama urbana que, en tanto que base articuladora del espacio, se cierra en 1219. Además, en su desarrollo intervendrían dos factores esenciales, uno de tipo económico (vías comerciales y tráfico de personas y mercancías, sin duda) pero también otro político y de vertebración y control del territorio por parte del monarca otorgante de los privilegios. Incluso en la orientación viaria también puede detectarse un interés político en el que ahora no es posible entrar. Se atendía entonces a la articulación del espacio y a los ámbitos de control de estos centros urbanos $-\mathrm{y}$ de sus intereses-, a la formación de una red y al sentido que la explica. El punto de llegada en los inicios del siglo XIII, y recordando las ajustadas dimensiones del reino, da como resultado una trama espesa, con centros urbanos de dimensiones esencialmente reducidas pero con una jerarquía no muy clara. También con abundantes ejemplos de funciones de dudoso perfil urbano, por más que los estatutos jurídicos digan otra cosa. Todo ello tenía un sentido y encuadre en el marco cronológico ahí anotado y en el territorio analizado, y casi pedía un análisis semejante para el resto del período medieval, donde diversos factores irán despejando este paisaje y definiendo un reducido número de centros urbanos jerárquicamente más relevantes.

La propuesta de partida ahora pretende analizar, por tanto, el desarrollo ulterior de aquella red plenomedieval, que considero completada a principios del siglo XIII sobre principios ligados a la construcción territorial y del poder regio, en primer lugar, y ligada asimismo a la estructura viaria. Se había cerrado una etapa, y la que sigue tiene nuevos elementos relevantes. El análisis bajomedieval, desde esta perspectiva distinta, es muy pertinente y nos va dirigiendo a otros parámetros: esencialmente se "depura" un sistema progresivamente jerarquizado, donde es posible distinguir niveles y prioridades. La trama ya no es tan homogénea, aunque sus estatutos urbanos puedan serlo, e intervienen otros centros jurídicamente secundarios. Lo que se pretende

\footnotetext{
${ }^{4}$ Ramírez Vaquero 2015.
} 
mostrar aquí es cómo, asentado aquel tejido que, sobre todo a causa de sus estatutos reguladores hay que calificar de urbano ${ }^{5}$, a partir del siglo XIII se va articulando un desarrollo de otro tipo; se va produciendo una selección concreta de entidades que son las que crecen y desarrollan fisonomías más complejas. Y se establecen relaciones entre ellas. Este proceso permite presentar un sistema urbano más coherente con los rasgos más propios de la vida ciudadana, con un peso demográfico más sólido y con unas funciones económicas, políticas y religiosas, sobre todo.

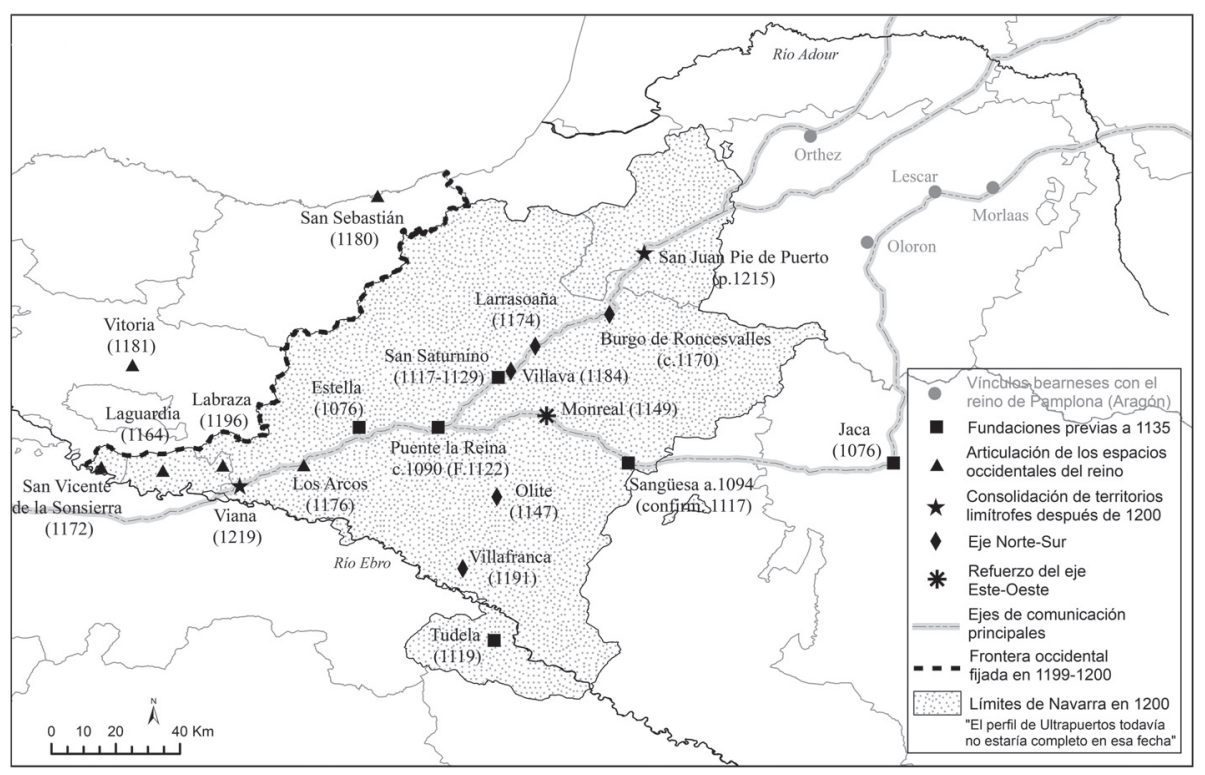

Mapa 1. Despliegue urbano 1135-1219.

El guión de este dossier propone como objetivo el análisis de la jerarquización urbana, de la red o del sistema, y en esa directriz se ha planteado ahora esta visión del caso navarro, que normalmente no se ha atendido desde este punto de vista. A lo largo de la baja Edad Media se va articulando un sistema más claro, donde ciertas jerarquías se van evidenciando de forma con-

${ }^{5}$ La concesión de un fuero de franquicia define, al menos en Navarra, la condición urbana del núcleo en cuestión y de sus habitantes, enfranquecidos de toda carga señorial y con las medidas de control de inmigrantes locales y de estamento campesino o clerical que a veces afloran; véase sobre todo Martín Duque 2002. Así se explica, entre otras cosas, esa profusión de núcleos técnicamente urbanos pero con frecuencia de muy reducido tamaño y limitado desarrollo económico: cuentan con un fuero de franquicia. Sólo los núcleos con estos estatutos, además, aparecerán luego representados en las Cortes del reino. 
tundente: ese es el proceso abordado en este trabajo. Interesa ir más allá del caso particular de cada ciudad por separado, como se ha hecho hasta ahora, buscando su impacto, saliendo de su ámbito de influencia; en definitiva, prosiguiendo la línea de trabajo iniciada en $2015^{6}$. Cabe resaltar que varios trabajos se han ido centrando en este tipo de visiones: entre los temas de investigación comparada propuestos por T. de Hemptinne en uno de los seminarios bienales de la Universidad Nova de Lisboa, estaba precisamente el de considerar el lugar que ocupan las villas medievales en su entorno regional, tanto desde el punto de vista físico como político, económico y social; cómo se inscribe el fenómeno urbano en un territorio más amplio, cómo perciben sus contemporáneos el panorama global, cuál es su impacto ${ }^{7}$. Las dimensiones de este trabajo no permiten plantear un balance amplio de carácter historiográfico, o realizar una tarea comparativa con otros espacios, incluso solamente hispánicos; ese es, por otro lado, el objetivo del dossier completo. Sí cabe resaltar que el tratamiento del conjunto urbano -en tanto que red- a escala de reino, o de una región relativamente coherente, no es frecuente o, al menos, está necesitado de mayor atención ${ }^{8}$.

Para ello se planteará, en primer lugar, una brevísima reflexión relativa la situación de partida, para luego pasar al núcleo esencial de la propuesta. Ésta se desarrollará estableciendo dos apartados esenciales centrados en el proceso de jerarquización urbana entre el siglo XIII y el XVI. El primero de p. 15

${ }^{6}$ Con objetivos aún más ambiciosos, es lo que acertadamente planteaba Asenjo 2014,

${ }^{7}$ Hemptinne 2013, pp. 18-19. Los seminarios que dan lugar a esta publicación prestan frecuente atención a aspectos comparativos y a visiones "en red"; así por ejemplo el publicado en 2017 se centra en las pequeñas ciudades y dedica un apartado a "Pequenas cibdades em rede", con interés por la interacción y la jerarquía entre ellas: Costa, Andrade, Tente 2017.

${ }^{8}$ Fijar la perspectiva desde una línea elevada del horizonte obliga a análisis más próximos a las redes urbanas y sus interacciones, aunque el objetivo se centre en aspectos concretos, relativos a los mercados o las sociedades. La Semana de Estudios Medievales de Estella ha dedicado al menos dos ediciones, y sus respectivos volúmenes, a analizar fenómenos urbanos a escala europea o hispánica: una sobre mercados inmobiliarios y paisajes urbanos (Pamplona 2007), y la otra sobre las sociedades urbanas (Pamplona 2003). Asenjo 2003 desarrolla -en la segunda- un considerable esfuerzo de análisis demográfico urbano para el conjunto de los reinos de Castilla y Portugal que, entre otras cosas, plantea los temas en una perspectiva de interacción y conjunto. Eso la lleva a destacar el interés de estudiar los procesos de urbanización en sus marcos regionales. En ese mismo volumen, también Sesma 2003 propone un análisis de conjunto para la totalidad de la Corona de Aragón, analizando las diversas tramas urbanas y sus relaciones; la articulación de grandes, medianas y pequeñas ciudades y sus conexiones comerciales, viarias y políticas. Ruiz de la Peña 2003, que con carácter introductorio de ese tomo, plantea una visión general a escala peninsular, hará luego (Ruiz de la Peña 2007) una interesante reflexión sobre la trama urbana de la fachada marítima del Cantábrico, donde se inserta el modelo que va a analizar (Avilés). También Cherubini 2007, centra su trabajo en el marco de una red urbana, la toscana, a la que ha dedicado buena parte de sus estudios. 
estos apartados se ocupará del contexto de los nuevos estatutos que aparecen en este período, a partir de la mitad del siglo XIII, tanto si son concesiones nuevas en una trama ya suficientemente cargada como si son ensanches o ampliaciones de entidades preexistentes y en expansión. Valorar qué centros presentan un crecimiento de este tipo es también revelador. El segundo atenderá el nuevo rango que irá distinguiendo a determinados centros urbanos, y por tanto su nuevo lugar en el contexto de la red, progresivamente despejada. Con la información relativa a este cuestionario se han elaborado diversas tablas y un mapa final; las primeras, sobre todo, constituyen el armazón sobre el que se plantea la propuesta que aquí se presenta.

\section{EL PUNTO DE PARTIDA: LA RED CONSTRUIDA ENTRE 1076 Y 1219}

Está clara la plataforma de inicio, conformada desde el último tercio del siglo XI sobre la base de concesiones forales de franquicia ${ }^{9}$. Sus rasgos esenciales ya se han destacado (véase nota 3), pero cabe rescatar al menos tres aspectos de esa construcción que serán particularmente relevantes para lo que aquí interesa. Primero, que iniciado el siglo XIII se ha estabilizado el espacio regio, que quedará fijado para el resto del período medieval con mínimas variantes (unos $12.000 \mathrm{~km}^{2}$ ) $^{10}$; de ahí que en la tabla 1 se haya prescindido de Vitoria y San Sebastián. Segundo aspecto a retener: la red viaria básica ya está dotada de las infraestructuras esenciales; no quedan prácticamente carencias en este sentido, salvo para rutas más nuevas que pueda interesar vitalizar. Y en tercer lugar, aunque menos evidente a la vista del mapa 1 o de la tabla que sigue, la "capitalidad" del reino se sitúa hasta el siglo XIII en un plano esen-

\footnotetext{
${ }^{9}$ No deben confundirse con otras concesiones también llamadas "forales" en la historiografía navarra, pero destinadas a regular las rentas de la tierra de la comunidad campesina correspondientes (fueros "de unificación de pechas"), o con algunas destinadas a favorecer el asentamiento de poblaciones en zonas de expansión, con ciertas ventajas pero sin otorgamiento de franquicia (los llamados fueros "de frontera"). Un panorama general de los fueros locales de Navarra -entendiendo por tales a los que no son estatutos urbanos de franquicia- en Fortún 2007, pp. 865-900; el autor además sintetiza ahí otros trabajos previos sobre la cuestión, que huelga repetir aquí. Conviene resaltar que algunas de estas entidades pueden alcanzar un peso demográfico significativamente mayor que muchos núcleos oficialmente urbanos, pero su condición social es distinta y su caracterización jurídico-administrativa también. Es preciso señalarlo porque, de cara al periodo que ahora interesa, algunos de estos centros relevantes pero técnicamente no urbanos, adquirirán una importancia singular y acabarán entrando en la escena urbana alcanzando nuevos rangos.

${ }^{10}$ En general, las variaciones son menores hasta 1512 y no afectan a la cuestión que nos ocupa, salvo por una excepción. Desde 1461-1463, y en el contexto de la guerra civil de Navarra y la intervención castellana, las comarcas de Laguardia-San Vicente de la Sonsierra y Los Arcos, que cuentan con dos núcleos francos relevantes, pasan a Castilla. La última volverá a Navarra mucho después, en 1753, pero el resto no.
} 
cialmente ideológico, pero todavía de difícil plasmación física: Pamplona, cabeza del reino y señorío de jurisdicción episcopal, no reúne las instancias centrales de la monarquía, que apenas tienen cabida en la Civitas o en sus dos burgos nuevos. Ésta, precisamente, venía siendo una de las preocupaciones de la realeza desde el siglo XII y se completará en el final del siglo XIII y el XIV con evidentes consecuencias para la "conurbación" de los tres núcleos pamploneses.

Cabe destacar en la tabla $1^{11}$ un aspecto interesante en relación con el sistema urbano que se irá definiendo de cara al siglo XIII. Hay apenas tres núcleos donde se observa la existencia de "ensanches", o incremento de centros urbanos, que hubieran tenido lugar antes de 1219. Y hay un cuarto que, sin que tengamos constancia expresa del proceso de crecimiento de otros barrios o burgos, sabemos que su perímetro se había completado a finales del siglo XIII. Los modelos de Estella y Sangüesa saltan a la vista: se van concediendo estatutos nuevos a "barrios" que amplían el espacio urbano hasta finales del siglo XII. Pero además cabe interpretar que en Pamplona-sería el tercer caso- ocurre algo equivalente, aunque el crecimiento tenga un perfil diferente, generando burgos que crecerán con completa autonomía respecto a la Civitas original y de tradición antigua, que es precisamente la última en recibir un estatuto de franquicia. En todos los casos, además, las sucesivas ampliaciones contemplan concesiones forales cada vez menos restrictivas (es lo habitual en todas las concesiones de la segunda mitad del siglo XII, a partir de la de Olite), que acogen población local antes teóricamente veda$\mathrm{da}^{12}$. Cabe concluir, por tanto, que en el marco del desarrollo urbano previo a 1219 , y a pesar de esta intensidad de fundaciones, hay ya tres focos que van destacando en cuanto a su crecimiento demográfico y quizá su función económica: Pamplona, Estella y Sangüesa. El cuarto lugar donde se observa un crecimiento en barrios o burgos que se adjuntan es San Juan de Pie de Puerto, que para finales del siglo XIII cuenta con los de Mayor, San Miguel y San Pedro, donde además hay una interesante colonia de bayoneses, ligada seguramente al inicio de la actividad urbana de la localidad ${ }^{13}$. Cabría además destacar aún un quinto centro relevante en la tabla, que no evidencia

${ }^{11}$ La tabla se ha elaborado con las fechas de los estatutos reseñados en la bibliografía antes indicada. Los datos de población proceden, como en las tablas que siguen: para el siglo XIII de García Arancón 1985, pp. 76-77; para el siglo XIV de Carrasco 1973, sv. Los datos sobre las tierras de Ultrapuertos, que aparecen muy desigualmente en los libros de fuegos, cuando existen, se han completado con el estudio de Herreros 1998, pp. 180-185.

${ }^{12}$ La bibliografía ya señalada es recurrente sobre estas cuestiones; para el tipo de concesiones forales y sus condiciones (éstas y todas las que siguen) véase cualquiera de las obras citada en las notas 2-3, salvo indicación expresa de lo contrario.

${ }^{13}$ Herreros 1998, p. 181. 
aparentes ensanches ni crecimiento pero cuenta con una trayectoria previa singular y un indudable peso poblacional a mediados del siglo XIV. Se trata de Tudela, que en 1127 redefine mejor su estatuto inicial, derivado de la conquista de la ciudad apenas diez años antes.

Por tanto, en el primer cuarto del siglo XIII se detectaban cinco centros urbanos que, en cierto modo, van apuntando ya unos vértices prioritarios en el sistema urbano navarro. En la conurbación pamplonesa también la $\mathrm{Ci}$ vitas se ha equiparado, a finales del siglo XII, a un centro franco, como los burgos de su ensanche, o más precisamente, como el segundo de ellos. Estas líneas que ya se van anunciando serán importantes en la etapa que sigue, donde para empezar los cinco citados se consolidarán como cabezas de amplios distritos de gestión del patrimonio regio y por tanto de la articulación administrativa del reino: las merindades para el caso peninsular, y la castellanía de San Juan para las tierras de Ultrapuertos. En todos ellos acabará asentado luego, al menos, un representante superior del poder regio: el merino -el castellano o baile en San Juan- y luego el recibidor de las rentas de todo el distrito ${ }^{14}$.

\section{LA TRAMA URBANA BAJOMEDIEVAL: SS. XIII-XVI}

El panorama que se abre a partir de 1219 incorpora al menos dos coordenadas adicionales. Por una parte, es bien conocido que a partir de 1234 se produce en Navarra un cambio dinástico sustancial, con la llegada de monarcas procedentes de dinastías francesas. Esta situación abre la puerta a muy diverso tipo de influencias y novedades de toda índole. Por otro lado, el siglo XIII es también una etapa de crecimiento demográfico generalizado, con todo lo que esto supone para cualquier análisis de los centros de población y por más que la peste del siglo XIV los diezmara intensamente ${ }^{15}$.

\footnotetext{
${ }^{14}$ Una vez más Pamplona resulta singular, porque los merinos del distrito de Pamplona, llamada merindad de Las Montañas no residen allí, como era lógico esperar de un señorío ajeno, sino en el castillo de Garaño (valle de Ollo, a unos $15 \mathrm{~km}$. al noroeste de Pamplona). Desde 1350, incluso, hay dos merinos para todo el distrito, y tampoco residen en Pamplona. Véase, entre otros, Zabalo 1973, pp. 99-100 y 288-291.

${ }^{15}$ Es posible extraer algunos datos de población para el siglo XIII, por ejemplo del monedaje de 1265-1266 y de algunas otras piezas de mediados del siglo. Los datos de la tabla 1, ciertamente insuficientes (pero no se cuenta con otros), proceden de García Arancón 1985 pp. 76-77, y muestran un fuerte pico demográfico en los años centrales del siglo XIII que se corresponde con lo que también trasluce Felones 1982, pp. 129-210 y 623-714. García Arancón considera que la pérdida global de población tras la peste negra (1348) sería del 40\% (p. 76). En todo caso, sorprende la bajada brutal en Villafranca entre ambos momentos, en tanto que la subida de Laguardia quizá tenga que ver con una concentración de población en el burgo centralizador de una vasta comarca de aldeas. Hay que decir, en cualquier caso, que no se ha realizado un estudio más específico de la demografía del siglo XIII, que ciertamente tiene serias dificultades, dada la precariedad de las fuentes.
} 


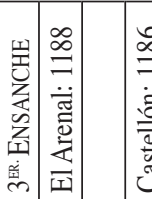

\begin{tabular}{|c|c|c|c|c|c|c|c|c|c|c|c|c|c|c|c|c|c|c|c|c|}
\hline 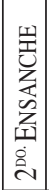 & 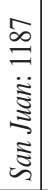 & & 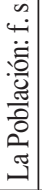 & & & & & & & & & & & & & & & & & 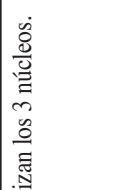 \\
\hline 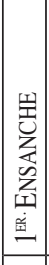 & 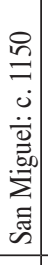 & 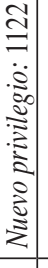 & 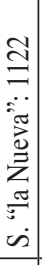 & & & & & & & & & & & & & & & 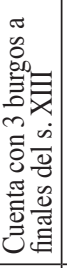 & & 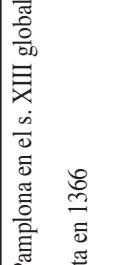 \\
\hline 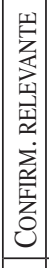 & $\underset{O}{=}$ & & $\Xi$ & 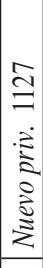 & & & & & & & & & & & & & & $\stackrel{\infty}{\Xi}$ & & 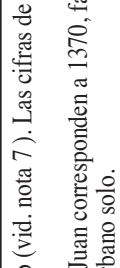 \\
\hline 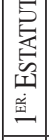 & $\begin{array}{l}0 \\
\vdots \\
0 \\
ن \\
\end{array}$ & $\begin{array}{l}\stackrel{8}{8} \\
\dot{0}\end{array}$ & $\begin{array}{l}\mathbb{Z} \\
8 \\
\dot{0}\end{array}$ & $\stackrel{\varrho}{\Xi}$ & $\stackrel{\beth}{\Xi}$ & 导 & $\stackrel{\text { g }}{=}$ & $\underset{t}{=}$ & $\begin{array}{l}\stackrel{尺}{\Xi} \\
\stackrel{\Xi}{0}\end{array}$ & $\cong$ & 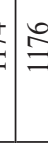 & $\stackrel{\infty}{=}$ & $\mid \begin{array}{l} \pm \\
= \\
\dot{J}\end{array}$ & $\stackrel{ \pm}{=}$ & $\vec{\partial}$ & $\stackrel{\circ}{=}$ & త్రి & $\begin{array}{l}\stackrel{2}{\beth} \\
\text { ¿ }\end{array}$ & $\stackrel{\Xi}{\beth}$ & 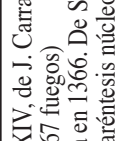 \\
\hline 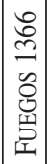 & స్ & 흐 & $\mathscr{f}$ & $\overline{2}$ & 筞 & $\begin{array}{l}\text { 辡 } \\
\stackrel{+}{+} \\
\end{array}$ & 天े & $\begin{array}{l}\widehat{\sigma} \\
\hat{\sigma} \\
\infty \\
0 \\
0\end{array}$ & $\approx$ & $\begin{array}{lll}\mathscr{\sim} & \alpha \\
& \alpha\end{array}$ & $=\underset{\approx}{\approx}$ & $\begin{array}{l}\infty \\
\infty \\
0 \\
\infty \\
\infty\end{array}$ & 守 & $\approx$ & कo & $\ddot{n}$ & & 寻 & 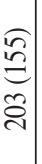 & 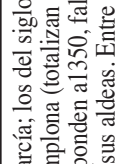 \\
\hline 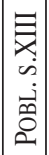 & $\underline{\Xi}$ & & 官 & 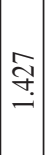 & 吕 & \begin{tabular}{l}
8 \\
\hdashline \\
$=$
\end{tabular} & & $\stackrel{q}{m}$ & & & & & & & ్ㅠ & & & & & 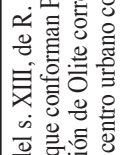 \\
\hline 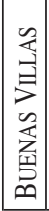 & 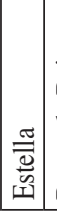 & 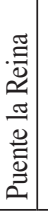 & 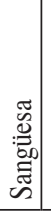 & $\frac{\frac{\pi}{0}}{\frac{\pi}{3}}$ & 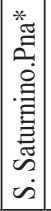 & :气 & $\mid \begin{array}{l}\overrightarrow{\overparen{J}} \\
\stackrel{3}{0} \\
\stackrel{\Sigma}{\Sigma}\end{array}$ & 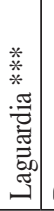 & 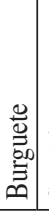 & 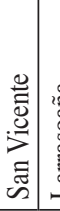 & 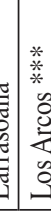 & 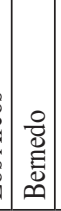 & 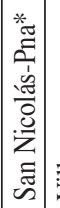 & 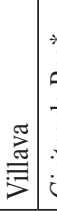 & 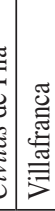 & 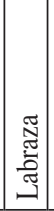 & 荧 & 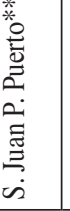 & 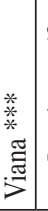 & 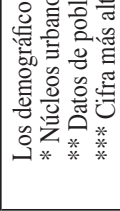 \\
\hline
\end{tabular}




\subsection{Los nuevos estatutos urbanos: ss. XIII-XVI}

Una de las cuestiones a tener en cuenta al inicio de la etapa que sigue es que en absoluto está cerrada a nuevas concesiones forales, si bien su contexto y sentido difieren de los del período precedente: éstas se van desgranando a lo largo del resto del siglo XIII -sin duda en ese marco de expansión demográfica- e incluso prosiguen hasta entrado el siglo XVI. Este panorama es muy interesante, y será ahora objeto de atención, atendiendo a sus contextos e intereses.

Los datos adquieren ahora una mayor complejidad, como se puede observar en la tabla $2^{16}$, donde se recogen las concesiones de estatutos y otros privilegios relevantes hasta el siglo XVI (en algunos casos el XVII). En una primera visión global, destacan tres momentos diferentes y tres casos singulares: El primero alcanza hasta los años centrales del siglo XIV; le sigue -segundo momento- una etapa de parón casi completo, seguramente relacionado con la regresión demográfica de la peste de 1348. La ya evidente densidad de la trama urbana podría ser otro aspecto interesante a destacar en estas fechas. Un tercer momento es el que se inicia ya comienzos del siglo $\mathrm{XV}$ y, con diversos vaivenes, se mantiene hasta el final del siglo y entra en el XVI. Los casos singulares antes destacados son los referidos a las localidades de Urroz, Aibar y Corella. En éstas se otorga hacia mitad del siglo XIV -en Urroz a finales del XIII- un primer privilegio tendente a la consideración urbana, o al menos a valorar funciones de carácter distintivo, que a la postre acaba desembocando, años después, en concesiones efectivamente de estatutos urbanos. Conviene analizar cada una de estas etapas y casos singulares por separado.

Las singularidades señaladas corresponden, como se ha adelantado, a un primer privilegio excepcional -el derecho de mercado de Urroz en 1286-1287 es el más sencillo- que reciben estas villas de condición campesina, ciertamente, pero con evidente peso demográfico (en comparación con el resto, sin duda), y que acabarán recibiendo el rango de buena villa mucho después ${ }^{17}$. En cierto modo, puede detectarse en los tres casos una cierta llamada de atención al rango que realmente deben ostentar centros de población que, sin estar dotados de estatutos urbanos, de franquicia, cuentan

\footnotetext{
${ }^{16}$ Los datos de población proceden de Carrasco 1973 como en la tabla 1. Para Labastide Clairence y San Juan de Pie de Puerto no hay información en los libros de fuegos; Herreros 1998, pp. 205-207 señala 130 fuegos para Labastide en 1350, pero la evolución de los censos por casa denuncia una espectacular caída hasta los 41 fuegos de 1370.

${ }_{17}$ Aibar presenta una secuencia muy interesantes desde su regulación pechera en el siglo XII, hasta la hidalguía colectiva a finales del XIV, para luego desembocar en la secuencia de privilegios diversos del siglo XV y XVI. Véase especialmente Miranda 2008.
} 
con perfiles demográficos y económicos de peso. Situaciones de este tipo presentan una interesante contraposición, ya entrado el siglo XIV, frente a núcleos oficialmente urbanos pero totalmente irrelevantes en cuanto a sus funciones y papel urbano.

Fijando la atención en la casi docena de concesiones de forales constatadas hasta mediados del siglo XIV primera etapa, hay que recordar que el proceso es bien conocido de manera individual y resulta innecesario detallarlo, pero interesa valorar al menos algunos aspectos relevantes desde la perspectiva de jerarquización urbana que nos atañe ahora. Como visión de conjunto, en primer lugar, todavía destacan aquí cifras demográficas claramente bajas, cuando no ridículas, que apuntan en casi todos los casos a intereses urbanizadores apegados a una intencionalidad política, de ordenación del territorio o de intento de promoción del poblamiento o de rutas viarias.

Un caso sobresale: el proyecto de sede para las instituciones de la monarquía, en Tiebas ${ }^{18}$. Desde un punto de vista geográfico resulta muy interesante, se trata de casi el centro físico del reino y a la vista de Pamplona, que sigue siendo señorío jurisdiccional del obispo. El empeño de los reyes champañeses por Tiebas es claro, pero a la larga fracasará un núcleo de claras deficiencias estructurales; el objetivo de convertirse en sede de reyes predominantemente ausentes, cuyas instituciones operativas no consigue aglutinar, lo abocará al fracaso. Destaca en segundo lugar, quizá, el interés por promocionar una vía de comunicación hasta entonces muy desasistida, de acceso directo a la costa. Es el único sentido posible de una fundación ciertamente minúscula en Lanz, en medio de la ruta al Bidasoa, también a la postre fracasada en tanto que realidad funcionalmente urbana ${ }^{19}$. No es ésta la ruta preferente hacia el mar, que tiende a desarrollarse a través de San Juan de Pie de Puerto, y Lanz quedará como un testimonio más de impulso urbano fallido, a pesar de un estatuto que equipara el centro con cualquier otro núcleo franco del reino, asiento en Cortes incluido. Y el tercer y último verdadero interés de la corona en el resto del siglo XIII parece centrarse en pequeños refuerzos de las comarcas limítrofes con Castilla y en una pequeña cabecera comarcal del sector oriental, Lumbier.

\footnotetext{
${ }_{18}$ Tiebas, Torralba y Lanz reciben fuero casi a la vez, cada uno según modelos distintos: el de Estella, para los primeros (aunque con matices para Torralba), y el de San Saturnino para el último, García Arancón 1985 p. 288. Los objetivos, en todo caso, son muy distintos.

${ }^{19}$ Los datos del censo por casas arrojan una población de 58 fuegos en 1266, García Arancón 1985 , p. 289, además de otros 6 fuegos despoblados ya entonces. El declive hasta mediados del siglo XIV es evidente.
} 


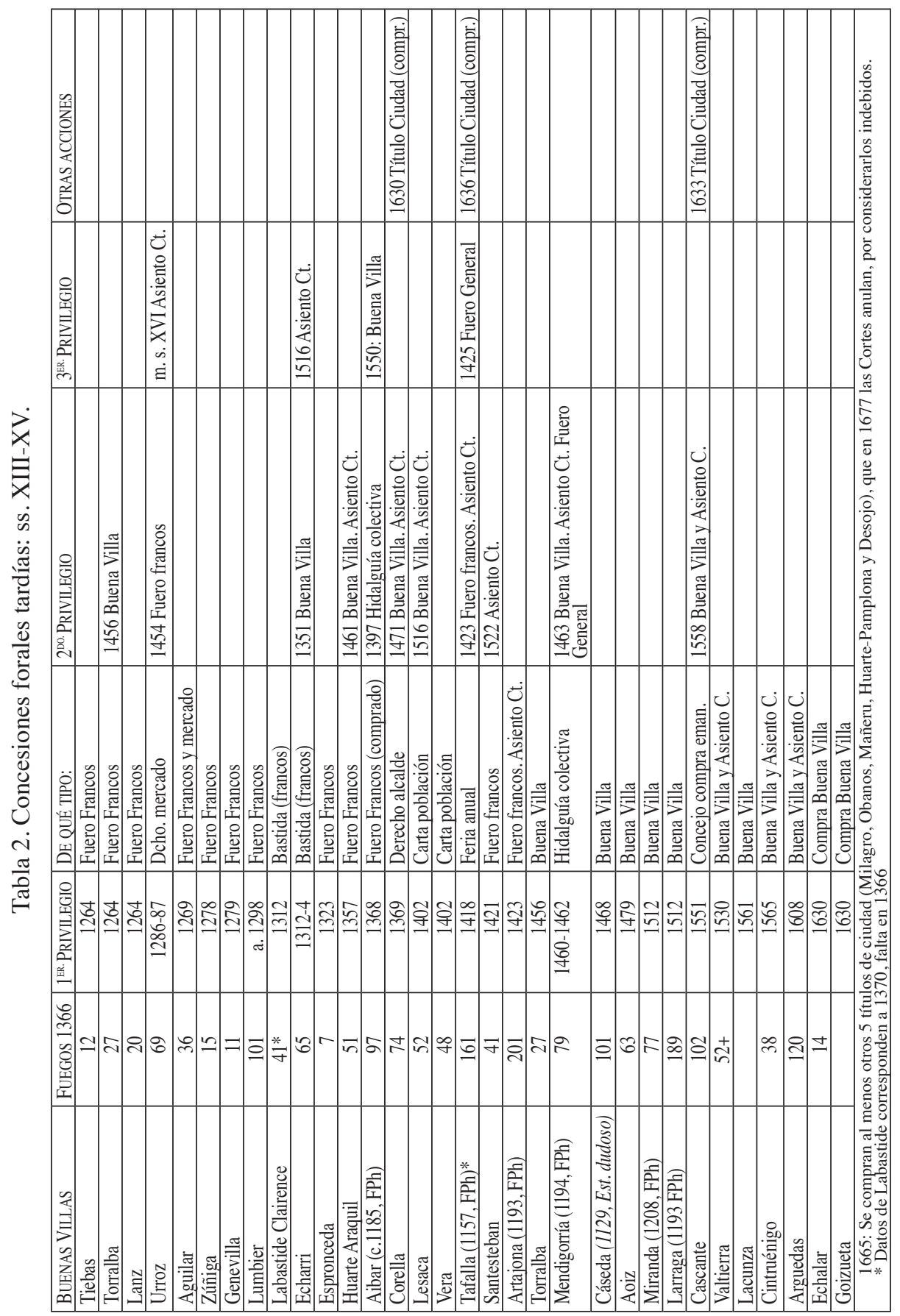


Interesa fijarse en un detalle significativo en toda esta primera fase. Por primera vez la concesión de un privilegio de franquicia se desliga de otros elementos hasta ahora siempre implicados en ella, o ligados al resultado de la misma. Por ejemplo, la condición de buena villa. En el siglo XV será frecuente, pero los primeros dos casos de lo que quizá cabe calificar como estatutos "incompletos" tienen lugar ahora: tanto en la bastida de Echarri Aranaz como en el núcleo urbano de Huarte Araquil la categoría de buena billa y el derecho a asiento en Cortes se reciben después y en tiempos diferentes, incluso un siglo más tarde para el primero. Lo mismo ocurre con Aibar o Urroz que forman parte de esos casos singulares antes indicados. Se trata de un fenómeno de inicio de concesiones escalonadas que también se completarán en el siglo XV o incluso después. En el caso de Urroz, y después del derecho a celebrar mercado recibido a finales del siglo XIII, a mediados del siglo XV -en plena guerra civil-, acabará recibiendo un fuero de francos igualmente "incompleto"; el proceso culminará con el derecho a asiento en Cortes ya en 1516, con los nuevos reyes de la monarquía hispánica. La secuencia sugiere una impresión de evoluciones lentas, al hilo de las circunstancias, o de avatares políticos que sirven de pretexto para la obtención de beneficios, o de un mayor lustre.

Finalmente, merece la pena destacar las concesiones forales ligadas a un claro interés de ordenación del territorio y el poblamiento en la primera mitad del siglo XIV, con un claro perfil defensivo, como ocurre con las bastidas de Echarri y Labastide Clairence, pero incluso también con Huarte Araquil. Ya se ha aludido al interés por la consolidación de las comarcas limítrofes hacia Castilla, con fueros de francos ciertamente singulares, como los de Aguilar, Zúñiga, Genevilla o Espronceda. Si Labastide Clairence protege un flanco aquitano, las otras dos también pueden interpretarse como opciones de protección frente a Castilla, aparte de como articuladoras del poblamiento.

La segunda mitad del siglo XIV supone un momento de parón casi total en concesiones forales y promoción del poblamiento urbano. El colapso demográfico ocasionado por la peste en 1348 puede explicarlo, pero otros elementos lo complementan. La trama urbana estaba fijada desde inicios del siglo XIII y, como se ha intentado destacar, las concesiones posteriores responden a contextos en cierta medida distintos. En este período de estabilización, sin embargo, puede interesar volver la mirada hacia la vida que han proseguido algunas fundaciones previas a 1219 (tabla 3), que no han cesado su evolución en el resto del siglo XIII, ni durante esta fase de aparente inmovilismo urbano general. Cinco de aquellas buenas villas reciben desde mediados del siglo XIII privilegios específicos para la celebración de ferias: Estella 
y Tudela en 1251; Olite en $1267^{20}$; la Civitas de Pamplona en 1324 y Sangüesa en 1399. Es decir, en la segunda mitad del siglo XIII y en el XIV hay un determinado desarrollo -en este caso ligado a su peso comercial- en estos escenarios ya consolidados. Teniendo en cuenta que la feria de la Civitas podía interesar a la totalidad de la conurbación pamplonesa, cabe considerar que el desarrollo comercial y las correlativas industrias locales se concentran en las cinco cabeceras comarcales del reino, ya señaladas. Cuatro de ellas ya han sido resaltadas antes, y se definen como cabezas de merindad al menos desde la segunda mitad del siglo XIII; la quinta ahora destacada (Olite en vez de San Juan) alcanzará el rango de cabeza de merindad en $1407^{21}$. No hay que olvidar (tabla 2) el privilegio de celebración de mercado otorgado a Urroz a finales del XIII.

El perfil político del elenco de centros más relevantes no está exento de interés. Tanto Pamplona como Estella conocen en la segunda mitad del siglo XIII importantes movimientos de rearticulación urbana. En ambos se plantea una unificación de sus barrios o burgos en 1266, que sólo prosperará plenamente en Estella. La jurisdicción episcopal de Pamplona dificultaba sin duda cualquier proceso y, tras la "guerra de Navarra" (1276), Pamplona sólo mantendrá una unión parcial de los dos burgos nuevos: San Saturnino y San Nicolás. Pero desde 1319 el conjunto de Pamplona dejará ya de ser señorío jurisdiccional del obispo y desde 1321 se pondrá en marcha la repoblación de la Civitas -con su judería- destruida en la guerra de 1276. Aunque aquella primera unificación pamplonesa fuera parcial y convulsa, los proyectos de consolidación urbana iniciados en 1266 apuntan a una relevancia sustancial de ambos centros de población, el estellés y el pamplonés ${ }^{22}$. Lo interesante, además, es que se sigue reforzando el foco en un elenco determinado de entidades urbanas que, de aquella trama conformada entre el siglo XI y el XIII, van destacando por motivos económico-comerciales y, en algunos casos, políticos. La red inicial va distinguiendo jerarquías y funciones cada vez con más claridad; también descartando -quizá- otras opciones. Más adelante volveremos sobre ellas.

${ }^{20}$ García Arancón 1985, p. 120.

${ }^{21}$ Olite presenta una gran solidez urbana desde fechas tempranas, y ha conservado una riquísima documentación municipal; evidencia de este peso en el siglo XIII es el trabajo de Ciérvide, Sesma 1980, o el más reciente de Ilundain 2017.

${ }^{22}$ Sobre la situación de Estella en el siglo XIII, García Arancón, 1985 p. 289; sobre Pamplona, sobre todo Ramírez Vaquero 1998, pp. 229-244, y Miranda García 2011, pp. 217-243. 


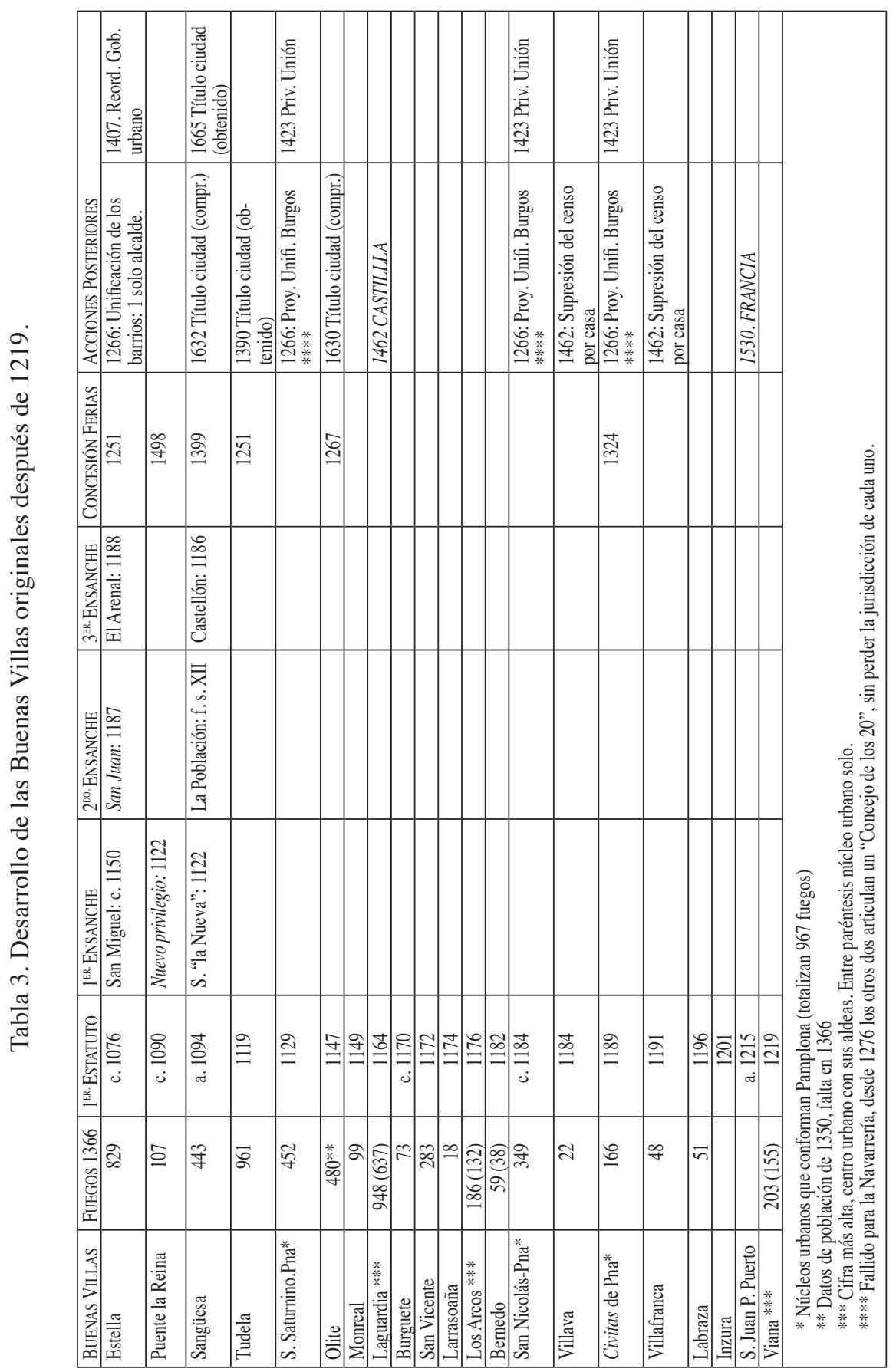


El tercero de los momentos de desarrollo urbano del reino, después del parón de mediados del siglo XIV, (tabla 2) se inicia a principios del siglo $\mathrm{XV}$ y presenta aspectos muy interesantes. Contamos con 18 centros que reciben privilegios de diverso tipo a partir de 1400, y hasta entrado el siglo XVII, y a ellos hay que sumar los casos antes aludidos donde se amplían derechos en localidades comentadas en el primer bloque. Siete situaciones corresponden ya a fechas posteriores a 1512, cerrando un largo proceso, si bien con otro tipo de motivaciones. En los once privilegios anteriores a 1512 destacan ante todo dos aspectos. Por una parte, la circunstancia de seis concesiones forales de franquicia -más de la mitad- a núcleos campesinos de un peso demográfico relevante, aunque estén muy por debajo de las densidades de población de las grandes buenas villas cabeza de comarca. Y por otra, pero muy relacionada con la anterior, se observa que estas entidades ya contaban con antiguas regulaciones de prestaciones y rentas señoriales (realengas) concedidas en el siglo XII y hasta el inicio mismo del XIII: los llamados fueros de unificación de pechas (FPh, en la tabla).

Otro hecho resulta de interés en esta fase. Aunque la misma se inicia en 1402 y se ha llevado hasta iniciado el siglo XVII, sólo se producen concesiones de franquicia y privilegios afines en el primer cuarto del siglo $\mathrm{XV}$; los posteriores tienen otros matices diferentes, que luego se comentarán. Se trata de cinco casos concretos hasta 1423 y merecen un breve comentario. Por una parte, se observa un aparente interés por consolidar centros que concentren población en la zona atlántica de Navarra, la cuenca del Bidasoa, desembocadura de aquella ruta directa impulsada por la fundación de Lanz en el siglo XIII: Vera, Lesaca y Santesteban reciben estatutos destinados a estos objetivos, aunque sólo el último (1421) es propiamente un fuero de francos. Vera y Lesaca reciben cartas destinadas a favorecer la población, indudablemente con algunos privilegios ventajosos. Resultan de gran interés los otros dos casos de este lote: Tafalla y Artajona. Ambas son entidades de labradores con fueros de regulación de pechas y se sitúan en la zona media de Navarra; la primera a escasos 4 kilómetros de Olite y la segunda protegiendo con su recinto amurallado las comarcas entre Olite y Estella. Cuentan además con un peso demográfico singular, más elevado que muchas de las entidades urbana y buenas villas reconocidas desde tiempo atrás. En ambos casos la concesión señala expresamente el derecho de asiento en Cortes, que desde el siglo XIII ya hemos visto no estaba necesariamente ligado a la franquicia. Tafalla, ciertamente, es foco de una atención particular: tras la concesión de derecho de celebración de feria en 1418 (es decir, hay un desarrollo comercial claro en el entorno) sigue el estatuto urbano con derecho a representación en Cortes y luego la adscripción al Fuero General de Navarra, todo ello en un plazo de ocho años. La cronología nos sitúa en el reinado de Carlos III, que puso espe- 
cial atención en el desarrollo de la vecina Olite como sede regia por excelencia y cabeza de un nuevo distrito de la monarquía desde 1407; pero Olite ya tenía un fuero de francos desde mediados del siglo XII, y un volumen demográfico relevante en el siglo XIV.

Una vez más, conviene fijarse en las cinco buenas villas cabezas de merindad, que provienen de la articulación urbana anterior al siglo XIII (tabla $3)$. En el siglo XV siguen ocurriendo cosas allí. Por una parte, Estella recibe en 1407 una nueva ordenación de su gobierno municipal, punto final de un largo recorrido de tensiones en el gobierno urbano que se retrotraen a inicios del siglo XIII y que habían implicado otros ensayos previos a finales del siglo $\mathrm{XIV}^{23}$. Por otro lado, se produce la definitiva unión de la conurbación pamplonesa completa, con anulación de todos los privilegios anteriores, el derrumbe de muros interiores, la creación de único consistorio -cuyo sistema se regulay la adscripción para todo lo demás al Fuero General de Navarra (1423). Este último asunto reviste cierto interés porque no es el único caso en que se recurre ahora al Fuero General para regular la convivencia urbana; precisamente en Tafalla, dos años después de la concesión de franquicia (1425) el núcleo urbano se adscribirá también al Fuero General, como ya se ha señalado. Esta es una modalidad interesante, que quizá guarde relación con el hecho, que vamos viendo desarrollarse desde el período anterior, de que la concesión de franquicia había dejado de implicar otros elementos anejos que antes no faltaban, por ejemplo el asiento en Cortes. Dos cuestiones pueden ser relevantes. La primera, que a estas alturas la población del centro urbano beneficiado por los cambios de estatuto no presenta una homogeneidad social, ni se busca: su población cristiana es nobiliaria, franca y campesina ${ }^{24}$; la representación en Cortes, por tanto, puede ser compleja. Y la segunda, que parece razonable considerar cómo lo que interesa en los estatutos urbanos concedidos a partir de un determinado momento es, por un lado, las condiciones sociales ligadas a la exención de cargas de carácter señorial -nobles y francos-y, por otro, la capacidad de gestión propia. El Fuero General recoge perfectamente los derechos y condiciones de los francos o ruanos, y los de todo posible poblador de ese centro urbano, que ya no tiene un perfil humano uniforme. Remitir a él es más que suficiente para regular la convivencia; de hecho, supone una mayor garantía de atención hacia los derechos específicos de cada uno. Por otro lado, el

\footnotetext{
${ }^{23}$ Ramírez Vaquero, 2018 (en prensa).

${ }^{24}$ En Tafalla en concreto (como en diversas villas pecheras del reino) hay menciones expresas al "concejo de labradores de la villa" (1374: AGN, CO_DOCUMENTOS, Caj. 29, N.1,1, f. 9v-2. Blanca y Juan II confirmarán su privilegio (1436), aludiendo a la "unión concedid[a] a los hidalgos, ruanos y francos de Tafalla", y recordando que los labradores habían sido elevados al rango de ruanos (AGN, CO_DOCUMENTOS, Caj.139, N.27).
} 
interés por el "buen gobierno", desatado ya en el último terco del siglo XIV, recomienda asimismo pensar en fórmulas unificadoras del Derecho. Ese papel lo desempeña el Fuero General de manera evidente, contemplando claramente los derechos y condicionantes de las "tres clases de gentes" y, por supuesto, de las minorías religiosas del reino, judíos y musulmanes.

Un fenómeno interesante tiene lugar en la segunda mitad del siglo XV y hasta 1512. Proliferan concesiones exclusivas de la condición de buena villa, una de ellas curiosamente precedida de una concesión de hidalguía colectiva. Conviene tener en cuenta, esencialmente, que estos casos se sitúan en los años de la guerra civil, y posteriores, y se enmarcan en un contexto de diverso tipo de exenciones y otorgamientos destinados a paliar el desastre cotidiano, por un lado, pero también la fidelidad a uno u otro bando. En la tabla 2 figuran las concesiones de este tipo que se vincularán, más tarde o más temprano, a estatutos urbanos, pero hay que resaltar que existen otros diversos privilegios de estas fechas relativos a exenciones totales o parciales de rentas señoriales y fiscales, concesiones de hidalguía colectiva, etc., del rey o del príncipe de Viana, y siempre en el marco de la guerra o de su subsiguiente crisis económica ${ }^{25}$.

Es interesante este lote del siglo XV, y hasta 1512, de núcleos que acaban definidos como urbanos por el correspondiente estatuto y representación en Cortes, que se otorga ahora, que pueden tener cierto peso demográfico pero que no tienen tradición alguna de funcionalidad urbana. Ya se ha indicado que algunas de estas localidades habían tenido fueros reguladores de rentas señoriales (FPh en la tabla) y de los llamados de frontera (FF), como ocurre con Cáseda ${ }^{26}$. Una vez más el contexto es esencial para valorar las concesiones del siglo $\mathrm{XV}$, que se producen cuando la realeza no percibe apenas rentas ni otros derechos señoriales, en medio de la guerra civil y sus coletazos posteriores hasta casi el inicio del siglo XVI. Los ingresos de la corona son casi nulos, como muestran los escasos libros de cuentas conservados, donde las rentas de la tierra están casi en su totalidad enajenadas o arruinadas, o no hay capacidad efectiva de cobro. Otorgar privilegios de este tipo (que implican la

\footnotetext{
${ }^{25}$ En particular sobre este tipo de concesiones, incluidas las indicadas en las tablas para estas fechas (el fuero de Urroz; la declaración de buena villa de Torralba; supresión censos de Villaba y Villafranca), véase Ramírez Vaquero, 1990. pp. 301-305. El caso de Mendigorría es curioso; la concesión de buena villa procede de Juan II (que además la adscribe al Fuero General) en premio a su resistencia frente a las tropas castellanas $(G E N, s v)$ Se otorgaba así un derecho a representación en Cortes que la hidalguía colectiva no incluía, porque el brazo de la nobleza en las Cortes navarras no se vincula a los elementos de la baja nobleza, sino a una representación nominal o personal. No hay un cuarto brazo, de la baja nobleza, en el caso navarro.

${ }^{26}$ Sobre éstos, y aparte de Fortún 2007 (en particular p. 874 para la fecha del primer privilegio de Cáseda, que modifica respecto a trabajos anteriores), véase sus propios trabajos señalados en ese mismo estudio.
} 
exención de cargas y rentas) no tiene ya consecuencias económicas para el monarca y sí, en cambio, suponen un premio de lealtad que otorga prestigio y refuerza lazos convenientemente. El "precio" del privilegio es ciertamente favorable a la corona. La concesión, incluso, de la capacidad de asiento en Cortes aneja a algunas de estas concesiones, y a varias posteriores en el siglo $\mathrm{XVI}$, no supone tampoco un elemento que preocupe especialmente a los reyes en estas fechas; la capacidad de cobro de subsidios concedidos por las Cortes está también prácticamente anulada. En todo caso cabría incluso plantear algo que aquí resulta imposible analizar: si no conviene a la corona, dadas las circunstancias de la intensa banderización nobiliaria, reforzar más bien el brazo representativo de los francos, frente al peso de la nobleza.

Aunque volveremos con más calma a valoraciones de conjunto, cabe adelantar ya que la noción de una "construcción urbana" ha perdido casi todo sentido en el siglo XV, y desde luego en lo que se anota del XVI. Los estatutos que se otorgan no persiguen realmente objetivos de ese tipo, como puede plantearse para la etapa final del siglo XI y el XII, hasta los inicios del XIII, o como quizá todavía puede detectarse parcialmente en los ensanches y concesiones hasta el siglo XIV. En el siglo XV sólo se modifica, en realidad, la condición social de la comunidad, su prestigio social, y en todo caso se avalan formas de gestión más autónomas, y a veces más eficaces. Pero nada de eso comporta el desarrollo de centros de función ni perfiles urbanos, salvo cuando se atiende a Pamplona y Estella, cuya articulación interna queda claramente modernizada en los ajustes de privilegios del primer cuarto del siglo XV. Cabe considerar, quizá, que en algunos casos se reconoce un peso demográfico y una relevancia mercantil y de centro de convocatoria local que merece otro tipo de encuadramiento jurídico más acorde con la realidad; es decir, se reconducen situaciones equívocas, o incoherentes. Ahí cabe situar los casos de lugares como Tafalla, Artajona, Larraga y Cáseda, por ejemplo, con más de un centenar de fuegos (Artajona con el doble, seguida de cerca por Larraga).

\subsection{Nuevos rangos: otro sistema urbano que nos dirige hacia los ss. XVI y XVII}

Uno de los rasgos más evidentes de la evolución que se acaba de analizar, al hilo de las concesiones forales y de otros privilegios desde 1219, es el diferente desarrollo de centros que -porque tienen el estatuto correspondiente- cabe calificar como técnicamente urbanos del reino. Cabe recordar sucintamente: se ha articulado una densa trama de entidades dotadas de franquicia hasta inicios del siglo XIII, que organiza el territorio de la monarquía 
y a la vez sostiene una trama viaria esencial, pero otros criterios vendrán a definir la jerarquía del sistema, ya en los siglos XIII al XVI y con un espacio político estable. Desde estos puntos de vista cobran relevancia dos aspectos importantes: el peso económico y funcional de estos centros urbanos y el rango que adquieren como marca diferenciadora. Es en este terreno donde se dibujará un mapa mucho más simple del que veíamos al inicio de este estudio; una jerarquía urbana que define un sistema concreto. Y para ello es preciso volver a la tabla 3 , donde son relevantes un conjunto de cambios, ahora en el rango y lugar que se ocupa respecto al resto.

Una de las novedades más interesantes del siglo XIV es la elevación de Tudela al rango de "ciudad" en 1390, que la coloca en segundo lugar en el "escalafón ciudadano", después de Pamplona ${ }^{27}$. Estrictamente hablando, el rango "ciudadano" de Pamplona corresponde inicialmente a la Civitas, el núcleo de la sede episcopal, junto a la cual se habían generado los nuevos centros francos en el siglo XII. Su comparecencia en las Cortes del reino, por ejemplo, se realiza siempre por separado y la unificación de todos ellos en una sola entidad no tendrá lugar hasta 1423, cuando "la muy noble y leal ciudad de Pamplona" reciba el Privilegio de la Unión ${ }^{28}$. La concesión tudelana, donde no hay sede episcopal en la Edad Media, puede guardar cierta relación con la situación de su iglesia decanal de Santa María, esencial en el organigrama eclesial del reino aunque no adquirirá rango catedralicio hasta el siglo XVII ${ }^{29}$, pero seguramente también con el peso que la propia localidad tiene en el panorama urbano navarro. Hay que tener en cuenta, además, otros proyectos que no llegaron a culminarse del todo por parte de Carlos III, relativos a la erección de una archidiócesis navarra ${ }^{30}$. El mismo proyecto repetirán luego Catalina de Foix y Juan III de Albret, añadiendo Lescar y Olorón (1500) $)^{31}$, siempre sin éxito. Los deanes de Tudela, junto a los priores de Roncesvalles,

\footnotetext{
${ }^{27}$ La elevación al rango de ciudad, e incluso su significado, no ha sido un tema particularmente tratado en Navarra, al menos para la Edad Media. La bibliografía esencial corresponde a casos del siglo XVI y XVII y es más bien descriptiva del momento y del documento.

${ }^{28}$ Sobre Pamplona la bibliografía es abundante y lo esencial ya se recogido en notas precedentes. El Privilegio de la Unión, en todo caso, fue objeto de publicación: Martínez Pasamar 1995.

${ }^{29}$ Desde 1239 el prior de Santa María de Tudela había adquirido el rango de deán y desde 1259 tenía derecho al uso de anillo y mitra, concedido por Alejandro IV a instancias de Teobaldo II, Fortún 1986, p. 139. La información sobre la concesión de anillo y mitra, que da al deán atribuciones cuasiepiscopales, procede del Archivo de Tudela, Fuentes, 1944, n. 1139; lo recoge igualmente Goñi 1962, n. 196.

${ }^{30}$ En 1406 Carlos III intentó obtener de Benedicto XIII una archidiócesis navarra, que amparara todos los territorios del reino que formaban parte de otras diócesis y articulara otras tres sedes episcopales: Tudela, Irache y Roncesvalles, sufragáneas de Pamplona, la sede metropolitana. El proyecto nunca llegó a término. Véase Fortún 1986, p. 139.

${ }^{31}$ Boissonade 2005 (1893), pp. 288-289.
} 
en todo caso, forman parte relevante del elenco de consejeros regios en el siglo XIV y principios del XV.

Estas cuestiones interesan porque, si bien en Tudela la concesión del título de ciudad no va ligado a la condición episcopal, evidencia una serie de rasgos urbanos singulares y una jerarquía evidente en el panorama global, después de Pamplona. Localizada en una vía comercial de primer orden, la ruta del Ebro, desde el punto de vista demográfico, resulta el núcleo urbano más grande del reino a mediados del siglo XIII y va después del conjunto de Pamplona en 1366 (véase tabla 1), aunque casi con el mismo número de fuegos. La elevación del rango es un signo distintivo muy relevante, un rasgo de prestigio que la sitúa en el mismo nivel urbano que la cabeza del reino, como cabecera quizá de todo el sector meridional. Teniendo en cuenta el interés de Carlos III respecto a que articulase una diócesis propia, convertirla en "ciudad" a finales del siglo XIV formó parte quizá de ese proyecto, que no se culminaría hasta el siglo XVII. Conviene tener en cuenta la intensa atención de este monarca hacia cualquier posible elemento de prestigio político de la realeza navarra, equiparándola a las cortes por las que con tanta fluidez se movía en el panorama coetáneo. Por otro lado, su atención a la consolidación de las estructuras urbanas del reino es clara y se focaliza precisamente en tres núcleos esenciales: Pamplona y Tudela, pero también Estella ${ }^{32}$.

No consta otra concesión ciudadana en el reino en el resto de la Edad Media, aunque a finales del siglo XV, posiblemente hacia 1472, Estella empieza a utilizar igualmente el título de ciudad ${ }^{33}$. Esta circunstancia no deja de ser una confirmación más de esa percepción evidente respecto a qué tres centros encabezan la jerarquía del sistema urbano navarro al final de la Edad Media. Ya se ha comentado que en 1407 Estella había recibido un nuevo sistema de regimiento, fruto de una larga secuencia de vaivenes y conflictos que se retrotraen a inicios del siglo XIII; el nuevo procedimiento de elección de alcalde y consistorio iniciado entonces supuso un avance interesante de cara a la mejora del gobierno urbano, que luego veremos reiterarse en el que se decida para Pamplona en el Privilegio de la Unión (1423). Estella se había consolidado como centro urbano de índole superior en la Navarra occidental, quizá muy particularmente desde la pérdida en 1462 de la comarca de Laguardia, el otro enclave de indudable peso demográfico en la zona sur del reino, en pleno valle del Ebro. Aunque parece ser más bien una situación de hecho que de Derecho

\footnotetext{
${ }^{32}$ Me refiero, en concreto, a la atención al adecuado "buen gobierno" de Estella y Pamplona, ya puestos de manifiesto en las líneas anteriores, con acciones concretas ligadas a sus estatutos y articulación interna y, ahora, a esta especial atención a la cabeza indiscutible de todo el sector meridional.

${ }^{33}$ Lo señala Lacarra 1949, p. 399.
} 
(porque no consta tal concesión ciudadana) a finales del siglo XV Estella se define por tanto como "ciudad", y en esta caracterización desde luego no hay vínculo alguno con la situación de una iglesia principal, que claramente falta en el caso estellés. Pero Estella es posiblemente el tercer mercado del reino, después de Pamplona y Tudela ${ }^{34}$. El interés por la concepción "ciudadana" habla ya aquí, más bien, de un rango prestigioso, que la distingue de otros porque efectivamente se percibe distinta.

Otra situación interesante en este contexto de rangos es la de Olite. Ciertamente no hay aquí una actuación concreta respecto a su condición urbana, pero su perfil es muy singular en el siglo XV. Por una parte, es una de las residencias regias prioritarias, que irá aumentando su peso desde finales del siglo XIV, aunque esto no es algo exclusivo. Más interesante aún es que ya desde los primeros libros de cuentas del patrimonio regio, a mitad del siglo XIII, Olite parece tener siempre un papel distintivo ${ }^{35}$, ligado quizá a la preferencia regia por esta residencia. El magnífico palacio que se construye desde el inicio del siglo XV no debe oscurecer la anterior residencia palaciega del siglo XIII, hoy en día Parador de Turismo. Parece claro que la deliberada configuración de un nuevo distrito propio de gestión del patrimonio regio en torno a Olite en 1407, reordenando territorios limítrofes de las otras cuatro merindades para crear una quinta, responde precisamente a una necesidad de control directo de las rentas y derechos reales para sostener la vida cortesana en la que, en estas fechas es, con diferencia, la sede regia principal ${ }^{36}$. No se modifica su estatuto urbano, cierto, pero ya era una buena villa de pleno derecho desde el siglo XII y siempre presente en Cortes, que adquiere ahora un rango superior, de cabeza de merindad. Esto la distingue y la distancia poderosamente de la vecina Tafalla, todavía entonces de rango social campesino, que devenga rentas y otros derechos a la corona, y que sólo más adelante en el siglo XV recibe estatutos urbanos, como ya se ha comentado.

El último caso, pero no menos importante, es el de Pamplona. La actuación regia aquí es bien conocida y ya se ha comentado, el Privilegio de la Unión (1423) reúne las tres jurisdicciones en una, remodela la trama urbana,

\footnotetext{
${ }^{34}$ Por ejemplo, es uno de los centros importantes del circuito mercantil de paños que mueven las compañías comerciales de los Cruzat en el siglo XV, pertenecientes a la alta burguesía de Pamplona, Ramírez Vaquero 2016.

${ }^{35}$ Las cuentas de sus recibidores de cuentas, prebostes, etc., tienen rango propio incluso en todo el largo período (hasta 1407) en que forma parte de la merindad de La Ribera. Se comprueba en cualquier registro de cuentas de merinos y bailes del reino, del Archivo Real y General de Navarra.

${ }^{36}$ El documento de erección de la merindad, de 18 de abril de 1407 (AGN, CO_DOCUMENTOS, Caj. 94, N.15), pone claramente de manifiesto esta centralización de rentas de un vasto cinturón conformado por 22 villas de realengo y diversos valles del entorno.
} 
extiende la condición de ciudad a la totalidad del nuevo núcleo unificado y sitúa a todo el conjunto bajo el Fuero General de Navarra. El cambio responde a una realidad muy clara; Pamplona es la cabeza del reino que incluso había dado nombre al mismo hasta el siglo XII. Desde que los reyes habían recuperado la jurisdicción y anulado la de los obispos (1319), Pamplona había ido centralizando más aún los instrumentos del gobierno del reino (los de imagen de la realeza ya los aglutinaba desde antes): sede frecuente de las Cortes, de la Cámara de Comptos desde 1365, asiento preferente del tribunal de la Cort e incluso residencia frecuente de los monarca, aunque la principal siga siendo Olite durante un largo período de finales del XIV y principios del XV. La noción de "capitalidad" se materializa de forma cada vez más evidente, y su condición de mercado también. Por destacar un aspecto relevante en este sentido, es centro neurálgico una trama de familias burguesas de indudable potencia mercantil, encabezada por los Cruzat, a los que antes se ha aludido respecto a Estella, con redes comerciales en todo el $\mathrm{Midi}^{37}$.

El balance es evidente, por tanto. La densidad de centros "técnicamente" urbanos es muy elevada a principios del siglo XVI, lógica heredera de una evolución que casi estaba cerrada en las puertas del siglo XIII. Pero las acciones regias en los siglos XIV y XV, aún abiertas a nuevas concesiones de privilegios, establecen escalas y desvelan jerarquías esenciales porque tienen que ver con cuestiones de prestigio y rango que hablan de otros parámetros: de las funciones comerciales y peso económico, y del peso político. No se trata ya de un interés por la articulación del espacio de la monarquía... e incluso cabe plantear que no es la iniciativa regia la que marca la pauta. A la inversa, es el peso urbano el que reclama la acción regia, enlazando sin duda estrategias territoriales o de fortalecimiento de rutas viarias, pero sobre todo atendiendo a otras funciones e intereses vinculados claramente al rango ciudadano. Esto último estaba prácticamente ausente en casi toda aquella miríada de núcleos francos del siglo XII. Ahora destacan poderosamente las cabeceras de cuatro distritos principales de la monarquía en la Navarra peninsular: Pamplona, Tudela, Estella y Olite. Es ahí donde el rey se mueve y donde se ventila el marco comercial y político del reino. Un quinto caso, Sanguiesa, se queda ahora relativamente al margen, fuera quizá de las rutas mercantiles más intensas y de los focos de poder principales, si bien su condición de cabeza de merindad le reserva un cierto reconocimiento jerárquico respecto al entorno.

\footnotetext{
${ }^{37}$ Ramírez Vaquero 2016.
} 


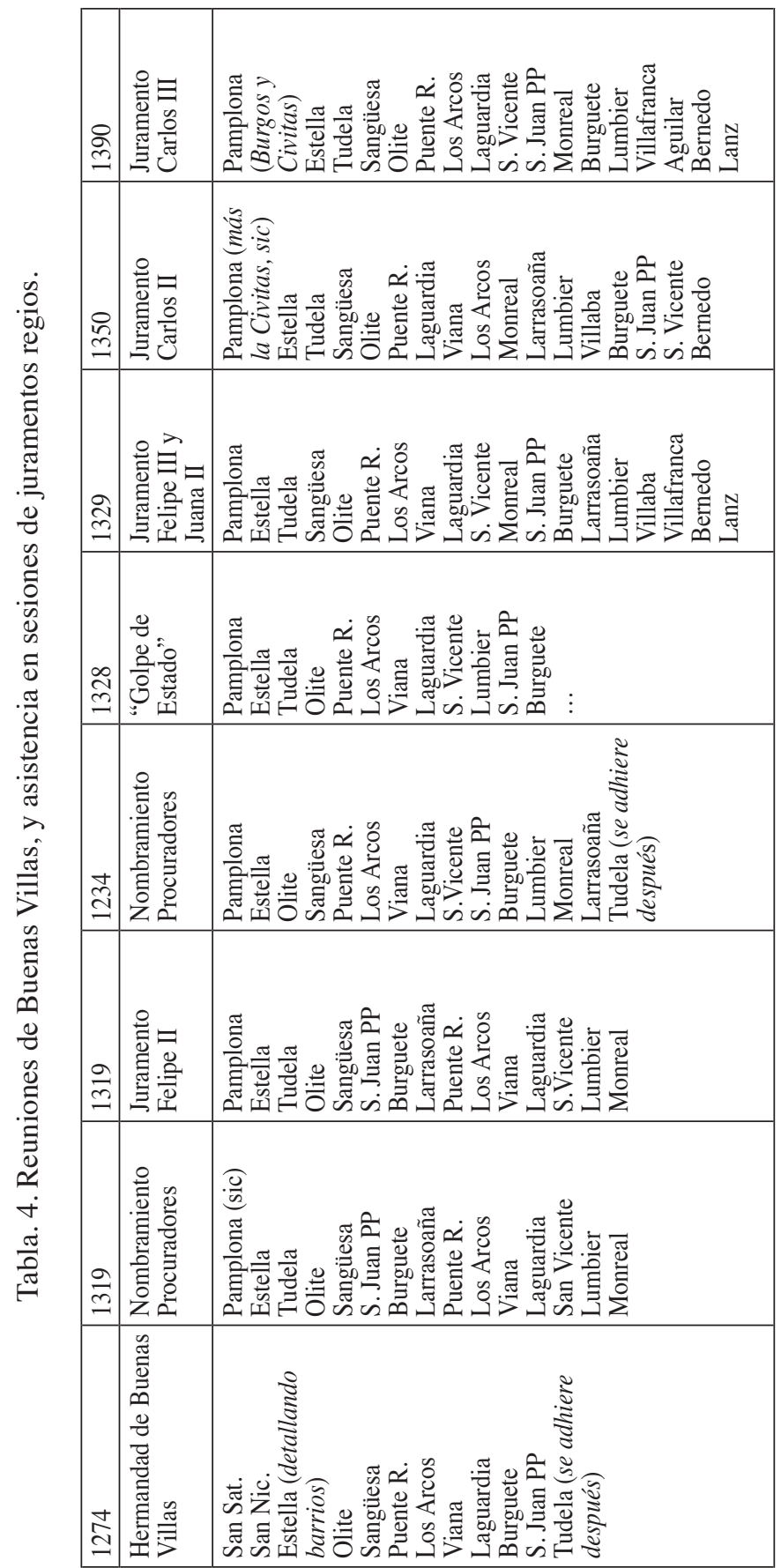


Un aspecto interesante para aquilatar estas cuestiones puede ser la posición que los centros urbanos ocupan en al menos dos momentos esenciales de la vida política del reino: las reuniones de Cortes y los cortejos vinculados a actos regios (coronaciones, por ejemplo). No es posible analizar ahora todos los elementos de este asunto (tabla 4), pero una mirada rápida hacia algunas reuniones de buenas villas a finales del siglo XIII y principios del XIV, y a los juramentos regios ${ }^{38}$, permite comprobar al menos algunas constantes: siempre la representación de Pamplona es la primera, tanto si se señalan burgos y Civitas como si no. Y siempre es Estella la segunda y Tudela la tercera, salvo cuando Tudela pasa al final porque se incorpora a la sesión o a la ceremonia en otro momento. En tercer lugar es evidente que se sitúa Olite, hasta que en un momento dado, a partir de la coronación de Felipe III y Juana II (1329), queda en cuarto lugar, adelantada por Sangüesa - ¿quizá porque su estatuto es más antiguo? Aunque no es necesario detenerse en todos los vaivenes que siguen, sí conviene observar que San Juan de Pie de Puerto, que hasta las crisis del primer cuarto del siglo XIV tenía una posición más bien elevada, baja rotundamente a lugares casi finales o medianos en la tabla. También interesa observar que Puente la Reina está siempre por delante de núcleos claramente más potentes, como Laguardia, Los Arcos o Viana misma, sin duda por el prestigio de ostentar uno de los estatutos primigenios del reino. Está claro, por tanto, que hay un grupo de cabeza incontestable: Pamplona, Estella y Tudela, a los que siguen Sangüesa y Olite. Son una vez más las cabezas de merindad, por supuesto, pero no puede ser éste el único motivo, dado que San Juan tiene jurisdicción equivalente en ese sentido y ha quedado muy preterida. Cabe detectar en algunos casos un componente de prestigio en la antigüedad del fuero, por un lado, pero sin duda es prioritario el peso político y económico de estos centros urbanos, que pone a Pamplona y a Tudela por delante de Estella.

\section{El SISTEMA URBANO NAVARRO A FINALES DE LA EDAD MEDIA. CONCLUSIONES}

El sistema que contemplamos en los inicios del siglo XVI presenta cambios muy significativos respecto al que veíamos a principios del siglo XIII. Si habitualmente la historiografía navarra ha valorado el pano-

${ }^{38}$ Lacarra, 1972: juramentos y nombramientos de procuradores de 1274 (núm. V), 1319 (núm. X y XI), 1324 (núm. XII), 1328 ("golpe de estado", núm. XIII), Felipe III y Juana II (núm. XIX). Para la coronación de Carlos II: Ruiz San Pedro 1997, doc. 3. Para la coronación de Carlos III, Osés 2005, Tomo I, doc. 143. 
rama urbano del reino en función de la condición jurídica de los diversos centros y de la secuencia de concesiones iniciales de cada núcleo, estrechamente ligadas a la ruta jacobea, el panorama adquiere otros matices si conjugamos todo lo valorado en las páginas precedentes. No hay duda de que el estatuto de franquicia es claramente definitorio de la "urbanidad" en el siglo XI y XII navarro; y lo es sin duda de la fijación de un elenco de buenas villas que quedaba esencialmente completado a principios del siglo XIII. No pierde prestigio luego, pero sí cambiarán los contextos de otorgamiento y los contenidos del mismo. En la construcción de aquella trama inicial entraban elementos de ordenación y control territorial, y de articulación viaria, pero en su densidad se distinguían mal otras consideraciones relativas a la jerarquía o las funciones propiamente urbanas. Apuntaban ya algunos pocos elementos esenciales: la relevancia de los núcleos pamploneses como cabeza del reino y la de Tudela como ámbito esencial en el espacio navarro del Ebro. También, quizá, se iba percibiendo el peso de las que poco a poco irán centrando luego, a lo largo del siglo XIII, los núcleos articuladores de la gestión de la monarquía: Estella, Sangüesa, Olite, San Juan de Pie de Puerto.

Es interesante valorar ahora otro mapa distinto, que recoja las realidades expresadas hasta finales del siglo XV, donde se cuentan 50 centros que jurídicamente ostentan el rango de buenas villas con asiento en Cortes. Mayor densidad, sí, pero ahora la jerarquización está muy clara, así como la función realmente urbana de apenas algo menos de media docena de ellas. También, en ese proceso, el relevo de algunos centros por otros. El nuevo mapa invita a repensar la respuesta a la pregunta que planea sobre el cuestionario aquí abordado: ¿Qué jerarquía urbana tenemos, y qué sistema de articulación de la trama urbana? A finales de la Edad Media la red es tupida, pero sólo si miramos las condiciones jurídicas de los centros. La imagen ha cambiado en muchos aspectos, y no sólo en el de la mayor densidad. La jerarquía está marcada ahora por claros elementos políticos: en primer lugar capitalidad y sede de las instituciones de la monarquía, o luego del virreinato (Pamplona), y no digamos centro de mercado; luego cabeceras regionales, también centros de mercado y de las instancias ejecutivas y judiciales. Es decir, localidades que ejercen una "capitalidad interna" en sus comarcas de referencia. Diversas han sido las intervenciones regias en la articulación de los gobiernos municipales, e incluso de sus jurisdicciones, al menos en Pamplona y Estella. Y dos claras "ciudades" se ponen de manifiesto ya a finales del siglo XIV, Pamplona y Tudela, más una tercera que se asomará a finales del XV. 


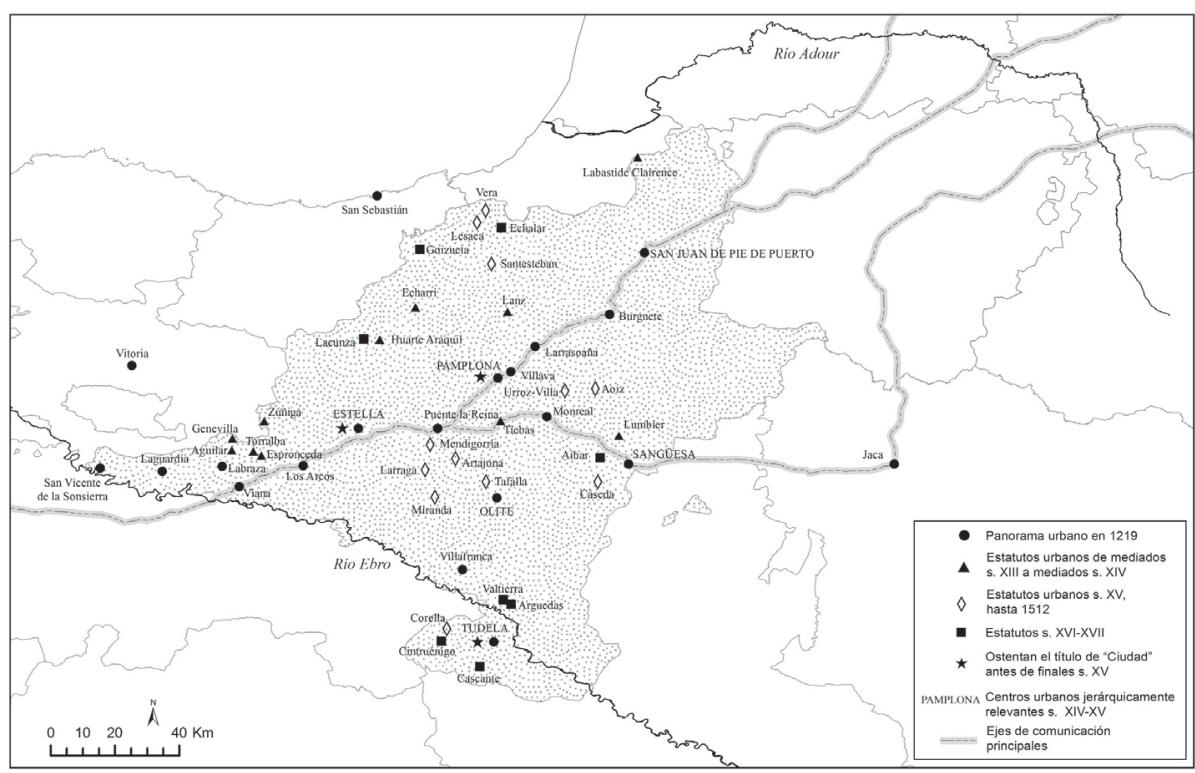

Mapa 2. Trama urbana de Navarra ss. XIII-XVI.

Sin ánimo de repetir ahora asuntos que ya se han señalado más arriba, conviene pensar en el sistema urbano aquí reflejado, recordando cuestiones que para Navarra no dejan de ser complejas: ¿Qué define la condición urbana? ¿Los aspectos jurídicos siguen siendo válidos a finales de la Edad media como criterio definidor? ¿Las condiciones económicas de exención de rentas señoriales que el estatuto de franquicia otorga.... mantienen en el siglo XIV y XV, sobre todo en este último (en que ya son inoperantes), el mismo atractivo? ¿Es, en cambio, el prestigio social lo que hace interesante la franquicia? Finalmente, ¿tiene sentido mantener estatutos campesinos, por holgados que fueran, en aglomeraciones de densidad, funciones y peso económico relevantes... sobre todo si se comparan con otras situaciones de franquicia urbanamente fracasadas? Es evidente que en la propia forma de plantear las preguntas está implícita la respuesta, que deriva de todo lo explicado más arriba.

Ya a finales del siglo XIV parece claro que las plazas urbanas realmente esenciales son dos: Pamplona, cabeza del reino y capital efectiva de la monarquía, y Tudela, segunda iglesia del reino y centro comercial y mercantil en el valle del Ebro. En ambos casos contamos con los dos picos demográficos más importantes, con volúmenes que rondan las 1.000 familias; y cuando Tudela adquiere el título de ciudad a finales del siglo XIV, ambas lo serán de manera contundente. A cierta distancia cabe situar a Estella, centro comercial 
en la ruta directa a Castilla y desde 1462 el centro urbano más potente en la Navarra occidental; a finales del siglo XV usa el título de ciudad, que cierra este tipo de rangos para localidades navarras ya hasta entrado el siglo XVII. Esta trilogía -Pamplona, Tudela, Estella- representa la cabeza jerárquica de una trama y reúne las funciones y papel esencial de la ciudad medieval. Sobre ella pivota el sistema.

En otro nivel, a clara distancia de las anteriores, se sitúan Sangüesa, la cabeza comarcal oriental, localizada en rutas comerciales secundarias y más locales, y (aunque sólo durante un período concreto, que no sobrepasa 1512) Olite, sede residencial de la realeza antes de entrar en el declive marcado, precisamente, por el cese de este papel. Un fenómeno interesante merece comentario, y es el auge de centros "jóvenes" en el perfil urbano; comunidades de rango campesino y peso demográfico importante, como pueden ser Tafalla (en vez de Olite) o Corella (no muy lejos de Tudela), que van adquiriendo un papel relevante en tanto que centros de referencia comarcal y comercial.

Pero, como ya se ha avanzado, el desarrollo urbano bajomedieval se asienta sobre tres elementos básicos, verdadero sostén del sistema: la capitalidad del reino, reforzada intensamente desde 1319, y sobre todo desde la unificación de la conurbación pamplonesa en 1423, que coincide además con una única sede episcopal propia; el desarrollo de mercados y centros comerciales de relevancia, como es el caso de Tudela-además segunda iglesia del reino, de rango "cuasi-episcopal"-; y el peso demográfico, que no sólo va ligado a las tres anteriores sino que también destaca en algunas de estas localidades emergentes en el siglo XV y sobre todo el XVI, de tradición original campesina, pero dotadas de una comunidad numerosa (Tafalla, Corella).

\section{BIBLIOGRAFÍA CITADA}

Asenjo González, María (2003), Demografía. El factor humano en las ciudades castellanas y portuguesas a fines de la Edad Media, en Las sociedades urbanas en la España Medieval: XXIX Semana de Estudios Medievales, Estella, 15 a 19 de julio de 2002, Pamplona, Gobierno de Navarra, Departamento de Educación y Cultura, pp. 97-150.

Asenjo González, María (2014), Presentación. Manifestaciones del impacto urbano en la Baja Edad Media, "Edad Media. Revista de Historia" 15, pp. 15-18.

Boissonade, Prosper (2005), Historia de la incorporación de Navarra a Castilla. Ensayo sobre las relaciones de los príncipes de Foix-Albret con Francia y con España (1479-1521), Pamplona, Gobierno de Navarra (Trad. de la obra original, editada en 1893). 
Carrasco, Juan (1973), La Población de Navarra en el siglo XIV, Pamplona, Universidad de Navarra.

Carrasco, Juan (1999), El Camino francés a Compostela y la dinámica de los asentamientos, en Itinerari medievali e idientità europea, Congreso Internazionale Parma, 1998, Bolonia, CLUEB, pp. 147-180.

Carrasco, Juan (2003), Sociedades mercantiles en los espacios urbanos del camino de Santiago (1252-1425). De San Juan de Pie de Puerto a Burgos, en Las sociedades urbanas en la España Medieval: XXIX Semana de Estudios Medievales, Estella, 15 a 19 de julio de 2002, Pamplona, Gobierno de Navarra, Departamento de Educación y Cultura, pp. 243-276.

Cherubini, Giovanni (2007), Políticas urbanas y mercado inmobiliario en las ciudades toscvanas, en Mercado inmobiliario y pasiajes urbanos en el Occidente Europeo: siglos XI-XV: XXXIII Semana de Estudios Medievales, Estella, del 17 al 21 de julio de 2006, Pamplona, Gobierno de Navarra, Departamento de Cultura y Turismo - Institución Príncipe de Viana, pp. 183-202.

Ciérvide Martinena, Ricardo; Sesma Muñoz, Ángel (1980), Olite en el siglo XIII. Población, economía y sociedad de una villa navarra en plena Edad Media, Pamplona, Diputación Foral de Navarra - Institución Príncipe de Viana.

Costa, Adelaide Millán da; Andrade, Amelia Aguiar; Tente, Catarina (eds.), (2017) O papel das pequenas cibdades na construção da Europa medieval, Lisboa, Instituto de Estudos Medievais.

Felones, Román, (1982), Contribución al estudio de la Iglesia de Navarra del siglo XIII. El Libro del Rediezmo de 1268, en "Príncipe de Viana" 43/165 pp. 129-210; 43/166-167, pp. 623-714.

Fortún Pérez de Ciriza, Luis Javier (1986), Organización eclesiástica, en Gran Atlas de Historia de Navarra. II. Historia, Pamplona, Caja de Ahorros de Navarra, vol. II, pp. 138-143.

Fortún Pérez de Ciriza, Luis Javier, (2007), Fueros locales de Navarra, "Príncipe de Viana" 68, pp. 865-900.

Fuentes Pascual, Francisco (1944), Catálogo de los Archivos Eclesiásticos de Tudela, Tudela, Diputación Foral de Navarra - Institución Príncipe de Viana.

García Arancón, Raquel (1985), Teobaldo II de Navarra, 1253-1270. Gobierno de la monarquía y recursos financieros, Pamplona, Gobierno de Navarra, Departamento de Educacion y Cultura - Institución Príncipe de Viana.

Goñi Gaztambide, José (1962), Regesta de las bulas de los archivos navarros (1198-1417), "Anthologica Annua” 10, pp. 577-593. (Reeditado 
2010: "Príncipe de Viana" 71, pp. 621-695 (Homenaje a José Goñi Gaztambide II. Selección de la obra dispersa sobre Historia Eclesiástica de Navarra de José Goñi Gaztambide).

Gran Enciclopedia de Navarra (1987), Pamplona, Caja de Ahorros de Navarra.

Hemptinne, Thérèse de (2013), Des sources pour une histoire des villes comparée? Essar de typologie thématique, en Andrade, Amelia Aguiar; Costa, Adelaide Millán da (eds.), La ville médiévale en débat, Lisboa, Instituto de Estudos Medievais, pp. 11-28.

Herreros Lopetegui, Susana (1998), Las tierras navarras de Ultrapuertos, s. XII-XV, Pamplona, Gobierno de Navarra.

Ilundáin Chamarro, Javier (2017), Los buenos hombres de Olite (siglos XII$X I V)$. Sociedad, poder y élites urbanas, Pamplona, Gobierno de Navarra - Ayuntamiento de Olite.

Lacarra, José María (1949), Ordenanzas Municipales de Estella. S. XIV y XV, "Príncipe de Viana" 10, pp. 397-424.

Lacarra, José María (1950), El desarrollo urbano de las ciudades de Navarra y Aragón, "Pirineos" 6, pp. 6-34.

Lacarra, José María (1972), El juramento de los reyes de Navarra (12341329), Madrid, Real Academia de Historia.

Martín Duque, Ángel Juan (2002), El fenómeno urbano medieval en Navarra, en Solórzano Telechea, Jesús Á.; Arízaga Bolumburu, Beatriz, El fenómeno urbano medieval entre el Cantábrico y el Duero, Santader, Asociación de Jóvenes Investigadores de Cantabria, pp. 9-51.

Las sociedades urbanas en la España Medieval (2003), XXIX Semana de Estudios Medievales, Estella, 15 a 19 de julio de 2002, Pamplona, Gobierno de Navarra, Departamento de Educación y Cultura.

Martínez Pasamar, Concepción (1995), El Privilegio de la Unión (1423) de Carlos III el Noble de Navarra, Edición, estudio filológico y vocabulario, Pamplona, Ayuntamiento de Pamplona.

Mercado inmobiliario y pasiajes urbanos en el Occidente Europeo: siglos XI-XV (2007): XXXIII Semana de Estudios Medievales, Estella, del 17 al 21 de julio de 2006, Pamplona, Gobierno de Navarra, Departamento de Cultura y Turismo - Institución Príncipe de Viana

Miranda García, Fermín (2008), Aibar, del fuero de unificación de pechas (finales del siglo XII) a la hidalguía colectiva (1398), "Príncipe de Viana" 69, pp. 377-394.

Miranda García, Fermín (2011), Pamplona, ciudad y señorío episcopal. Apuntes para un debate historiográfico, en Ciudad e iglesia: el espacio y el poder, la documentación y la expresión artística, León, Universidad de León - Instituto de Estudios Medievales pp. 217-243. 
Osés Urricelqui, Mercedes (2005), Documentación Medieval de Estella (siglos XII-XVI), Tomo I, Pamplona, Gobierno de Navarra, Departamento de Cultura (CODHIRNA. Serie II: Documentación municipal. Buenas Villas),

Ramírez Vaquero, Eloísa (1990), Solidaridades nobiliarias y conflictos políticos en Navarra. 1387-1464, Pamploma, Gobierno de Navarra, Departamento de Educación Cultura y Deporte.

Ramírez Vaquero, Eloísa (1998), Pouvoir seigneurial sur les «villes» de Pampelune de la fin du XIIIe au début du XIVe siècle, en Coulet, Noël; Guyotjeannin, Olivier (dirs.), La Ville au Moyen Age. II. Sociétés et pouvoirs dans la ville, París, CTHS, pp. 229-244.

Ramírez Vaquero, Eloísa (2015), El despliegue de la red urbana en Navarra. Espacios y movilidad entre el Adour y el Ebro (s. XII-XIII), "Príncipe de Viana" 76, pp. 71-108 (VIII Congreso General de Historia de Navarra. Ponencias)

Ramírez Vaquero, Eloísa (2016), L'écriture de la Bourgeoisie aux XIVe-XVe siécles. Un "Livre de Raison" de la famille Cruzat?, "Annales du Midi" 128, pp. 364-392.

Ramírez Vaquero, Eloísa (2019), Urban partialities and dissentions in Navarre, en Zorzi, A.; Asenjo González, María, Facciones, linajes y conflictos urbanos en la Europa bajomedieval. Modelos y análisis a partir de las ciudades españolas e italianas, Florencia (en prensa).

Ruiz de la Peña Solar, Ignacio (2003) Ciudades y sociedades urbanas en la España Medieval, siglos XIII-XV, en Las sociedades urbanas en la España Medieval: XXIX Semana de Estudios Medievales, Estella, 15 a 19 de julio de 2002, Pamplona, Gobierno de Navarra, Departamento de Educación y Cultura, pp. 17-50.

Ruiz de la Peña Solar, Ignacio (2007) Funciones y paisajes urbanos de las villas marítimas del norte de España: Avilés (siglos XII-XV), en Mercado inmobiliario y paisajes urbanos en el Occidente Europeo: siglos XI-XV: XXXIII Semana de Estudios Medievales, Estella, del 17 al 21 de julio de 2006, Pamplona, Gobierno de Navarra, Departamento de Cultura y Turismo - Institución Príncipe de Viana, pp. 691-736.

Ruiz San Pedro, María Teresa (1997), Archivo General de Navarra (13491381). I. Documentación Real de Carlos II (1349-1361), Donostia, Sociedad de Estudios Vascos (Fuentes Documentales Medievales del País Vasco; 76).

Sesma Muñoz, Ángel (2003), La población urbana en la Corona de Araón ( siglos XIV-XV), en Las sociedades urbanas en la España Medieval: 
XXIX Semana de Estudios Medievales, Estella, 15 a 19 de julio de 2002, Pamplona, Gobierno de Navarra, Departamento de Educación y Cultura, pp. 151-194.

Zabalo Zabalegui, Javier, (1973), La Administración del reino de Navarra en el siglo XIV Pamplona, Universidad de Navarra.

Fecha de recepción del artículo: octubre 2017

Fecha de aceptación y versión final: abril 2018 